\title{
A CONGENITAL FACTOR IN BRONCHIECTASIS
}

\author{
BY \\ D. J. CONWAY \\ From the Children's Department, University College Hospital, London
}

(Received for Publication September 20, 1950)

The majority of sufferers from bronchiectasis state that their symptoms began in childhood. There is good evidence for believing that the disease is usually of acquired origin, but in a few cases the presence of other developmental anomalies favours the view that there may also be a congenital factor.

Sauerbruch (1934) considered bronchiectasis was due to mechanical crowding, particularly of the left bronchial tree, during development and that some dilatation of middle-sized and large bronchi was present at birth, if the crowding and stricture occurred in late foetal life. Bronchial infection, secondary to measles, scarlet fever, pneumonia or pertussis, superimposed on the previous developmental condition, constituted bronchiectasis as seen clinically. He maintained that the absence of adhesions about bronchiectatic lobes, the normal appearance of the surrounding parenchyma, the absence of a history of pneumonia, and the irregularity of the layers of the bronchial wall were in favour of a congenital origin in this disease. Engel (1947) suggested the possibility of a congenital weakness of the bronchial walls in bronchiectasis in childhood. In Engel's view this inborn constitutional weakness is probably present in the condition known as congenital laryngeal stridor, and is also a factor in pulmonary collapse because of the individual susceptibility in the latter, which cannot be related to the viscosity of bronchial mucus.

Kartagener (1933) has deduced that bronchiectasis is mainly congenital from his observation that an extraordinary number of cases of complete transposition of the viscera also suffer from bronchiectasis. He quoted the figure of $25 \%$; Adams and Churchill (1937) found a similar proportion, but Olsen (1943) gave a lower figure, 16.5\%.

The frequency rate of occurrence of situs inversus totalis in the general population is:

At necropsy.....1 in 5,000 (Kartagener, 1933).

Clinically........1 in 10,099 (Adams and Churchill, 1937). Massachusetts.

1 in 19,500 (Cockayne, 1938). England.

By radiology....1 in 1,400 (Le Wald, 1925).
The appearance then of an uncommon condition, such as bronchiectasis, in $25 \%$ of cases with a rare anomaly like complete situs inversus suggests that there must be some definite relationship. Adams and Churchill are of the opinion that there are two types of individuals with transposition of viscera, perfectly normal mutants and monsters in whom other stigmata of malformation can be found, of which bronchiectasis is one. Olsen (1943), in 85 cases of dextrocardia, found 14 with bronchiectasis and 11 of the 85 patients had other congenital defects. Eliman (1935) described a case of situs inversus totalis, in which there was congenital pulmonary stenosis and physical signs of a cavity at the apex of the left lung. Certainly in the case of partial situs inversus congenital malformations are very common, and Maude Abbott (1936) found congenital heart disease in almost all her cases. Kartagener and Horlacher (1935) reported a case in the literature with partial situs inversus and bronchiectasis.

Cockayne (1938) from an extensive study of the literature and his own cases produced strong evidence that transposition of the viscera was a rare recessive character. If situs inversus totalis is a dominant or a recessive character it should affect both members of a pair of monozygotic twins or neither. Araki (1935) has recorded transposition in a pair of monozygotic twins. If heterozygotes for a recessive character marry there should be a proportion of one affected to three normal children, and in published cases the ratio works out at 1 to $3 \cdot 1$. The proportion of consanguineous marriages should be high. Cockayne found that there were $11 \%$ of first cousin marriages in the cases he studied.

A hereditary or familial influence has seldom been found in bronchiectasis, though Wiese (1927) noted that it was usually the younger child in a family who was affected, and Hinshaw and Schmidt (1944) and Pastore and Olsen (1941) recorded similar bronchiectasis in identical twins. Torgersen (1946) found transposition of viscera in three of the five children of one Norwegian family. All three had a 
productive cough which suggested bronchiectasis López Areal (1944) reported a family in which the parents were first cousins and three of their 11 children had transposition of the viscera and bronchiectasis.

In the literature on Kartagener's syndrome, the type of bronchiectasis recorded is usually tubular or varicose, instead of the cystic variety generally regarded as congenital. Clagett (1942) recorded bronchiectasis in 2 to $4 \%$ of routine necropsies; clinically, Kartagener (1933) found it in $0.25 \%$ and Adams and Churchill (1937) in $0.3 \%$ of cases. Nüssel and Helbach (1934) argued that the deduction of an inherent predisposition to bronchiectasis could not as yet be made because of the unreliable preceding history in most cases of Kartagener's syndrome. This syndrome, as described by Kartagener, includes nasal sinusitis, but it is improbable that there is a congenital liability to sinusitis and the bronchiectasis is secondary to it, because four of Olsen's cases with dextrocardia and bronchiectasis did not have nasal sinusitis and a further four cases had dextrocardia and sinusitis without bronchiectasis. On the other hand, Richards (1944) noted congenital absence of the frontal sinuses in bronchiectasis associated with transposition of viscera, and Andrews (1949) reported a case with small frontal sinuses, poorly developed ethmoid labyrinths and absence of sphenoidal sinuses and mastoid air cells.

The following three cases are typical examples of complete transposition of the viscera associated with bronchiectasis.

\section{Case Reports}

Case 1. This girl was first seen when $6 \frac{1}{2}$ years old because of a cough, anorexia, and poor weight gain for three years. In the past she had pertussis, aged 2 years: measles aged $2 \frac{1}{2}$ years; tonsils and adenoids removed aged 5 years. The parents were not blood relations and other siblings were normal. On examination the child was seen to be pale and thin. She had a nasal discharge, and a persistent productive cough with yellow sputum. There was an impaired percussion note in the chest, diminished air entry, and crepitations at the right base. The heart apex lay on the right side in the fifth space $\frac{1}{2}$ in. outside the nipple line: a systolic murmur at the apex was heard. The liver was palpable below the left costal margin. The Mantoux $(1100)$ reaction was negative. A radiograph of the chest showed transposition of the heart and abdominal viscera, and the maxillary antra that both were opaque. An ECG gave inversion of all primary waves in lead $I$, with R3 larger than R2. A right bronchogram showed varicose bronchiectasis in the right lingula and the right lower lobe bronchi (Fig. 1): the left bronchi were normal. The arrangement of the bronchial tree was a mirror image of the normal.

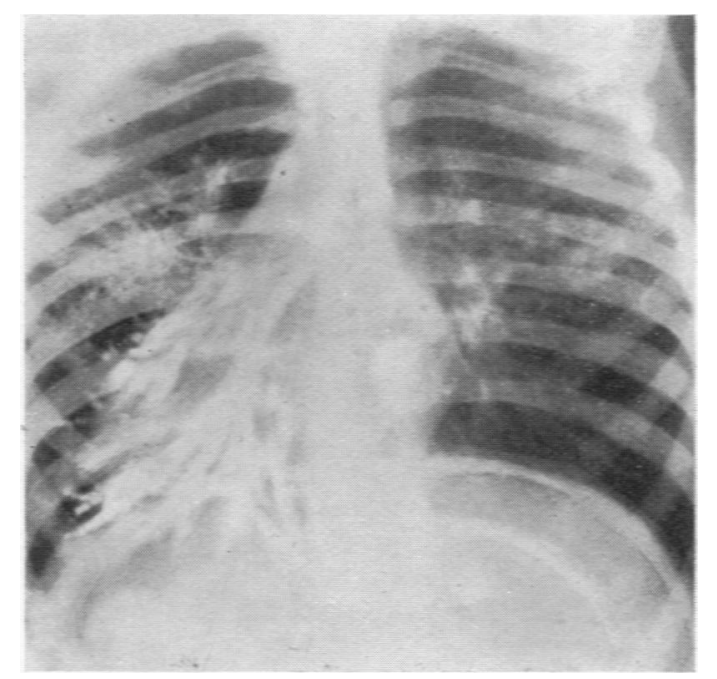

Fig. 1.-Varicose bronchietasis in the right lingula bronchi and right lower lobe bronchi.

Case 2. A man, aged 37 years, had had bronchitis all his life, with a cough productive of sputum. He had had nasal catarrh for 21 years, and slight retrosternal pain occasionally. He has spasms of coughing and feels that his chest is compressed if he lies on his right side when in bed. His cough is worse on rising, though he has it all the time, and often wheezes. His sputum is yellowish, never offensive, and more is brought up in wet weather, or when he bends down. He has had no haemoptyses.

He gave a history of pneumonia at the age of 1 year on the right side, and again on the right side at 12 years. In 1925 he spent a year in the army, and again in 1941-1942 (Grade B.2), but was discharged because of his chronic bronchitis.

On examination he was seen to be a pale, rather thin man, with slightly clubbed fingers. The trachea was central. The apex beat was heard in the right fifth interspace. Liver dullness was perceived on the left. The percussion note was impaired at the right base posteriorly with increased conduction of breath sounds and numerous moist rales. The physical signs were suggestive of collapse of the right lower lobe. There were moist sounds in the left midzone anteriorly and posteriorly.

A left bronchogram showed cystic bronchiectasis in the left middle lobe, and a right bronchogram bronchiectasis and partial collapse of the right lower lobe (Figs. 2 and 3). The right lingula segment showed mottled opacities and translucencies but the bronchi were not outlined.

Case 3. A girl, aged $8 \frac{3}{3}$ years, had had chronic nasal catarrh, cough, and wheeziness all her life. She was four weeks premature at birth, and in her past medical history she has had pneumonia on three occasions, measles, chickenpox, mumps and a tonsillectomy. The Mantoux reactions were negative. 

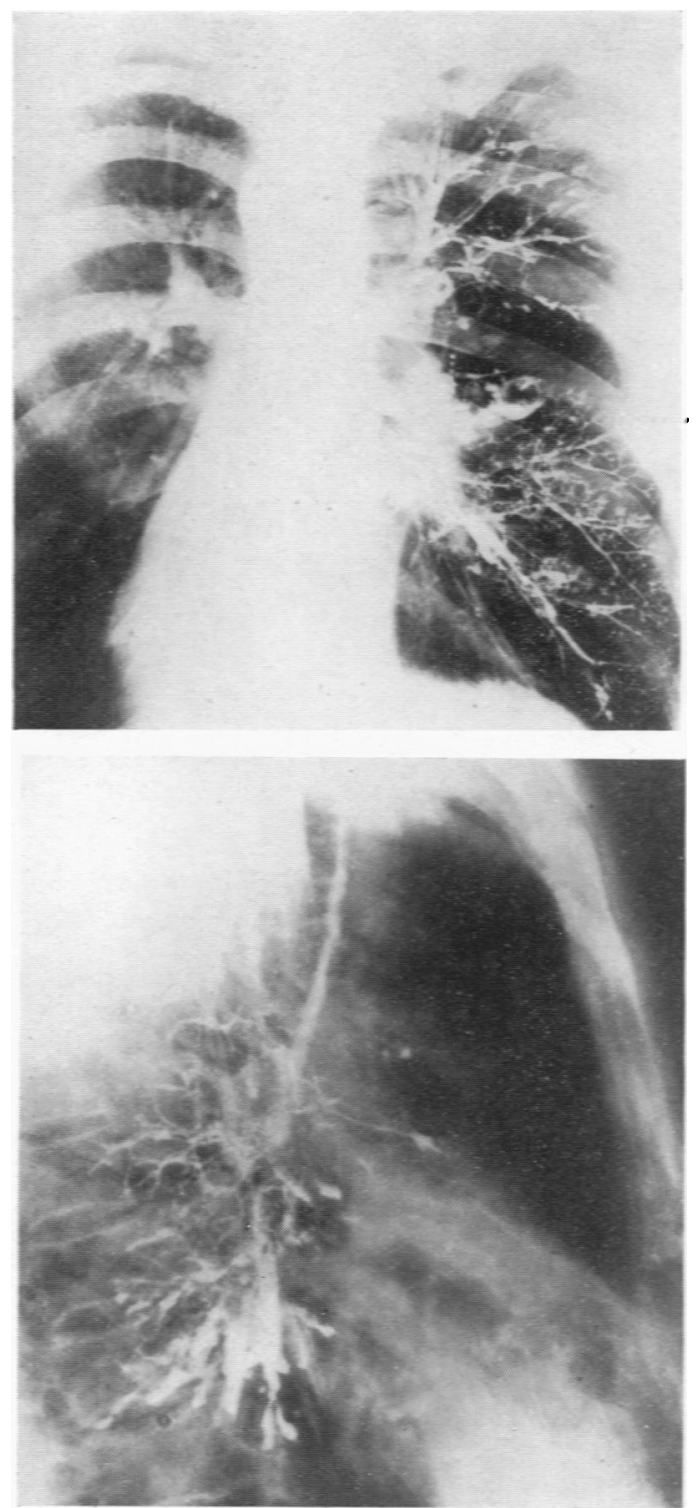

FIGS. 2 and 3.-Varicose bronchiectasis in some of the right lower lobe bronchi, and saccula bronchiectasis in the right lingula bronchi and left middle lobe bronchi.

The patient had two prematurely born male sibs who died in early infancy, one other brother who was killed in a road accident in early childhood, and one normal sister aged 7 years. The parents were second cousins. A first cousin of the patient also has transposition of viscera but no productive cough.

On examination she was seen to be a well built girl with chronic nasal catarrh and a cough productive of $4 \mathrm{oz}$. of sputum a day. There was moderate air entry and chest movements, and crepitations at both lung bases and a few scattered rhonchi. The fingers were not clubbed. The heart and abdominal viscera were transposed. An ECG showed the typical changes of a mirror image dextrocardia. The maxillary sinuses were opaque on radiography. Bronchography showed that the bronchial tree was a mirror image of the normal with bronchiectasis in the right lingula bronchi (Fig. 4).

It is probable that permanent pulmonary parenchyma as seen in adults develops only after birth and takes a matter of years. The development of the lung by differentiation, budding, and expansion of pulmonary anlages is usually fairly complete by about the age of puberty (Strukow, 1932; Willson, 1928, and Miller, 1934). Bronchiectasis may afflict those parts of the lungs which fail to expand after birth and remain in their foetal atelectatic state. The proper formation of alveoli does not occur in portions of atelectatic lung, so that the evacuating mechanism of an expulsive blast of air through the bronchi on expiration or coughing is not established. Secreted mucus may become infected if not removed adequately and bronchial weakening and dilatation would then occur. The centrifugal pull of negative intrapleural pressure probably has little effect on the bronchi while the infant's chest is still pliant and can be sucked in, but atmospheric pressure acting down them when they are unsupported externally by aerated alveoli can cause dilatation.

Heller (1885) and Francke (1894) attributed so-called congenital cystic disease of lungs to the saccular dilatations of small bronchi and bronchioles formed in atelectatic lung, and other writers ascribed

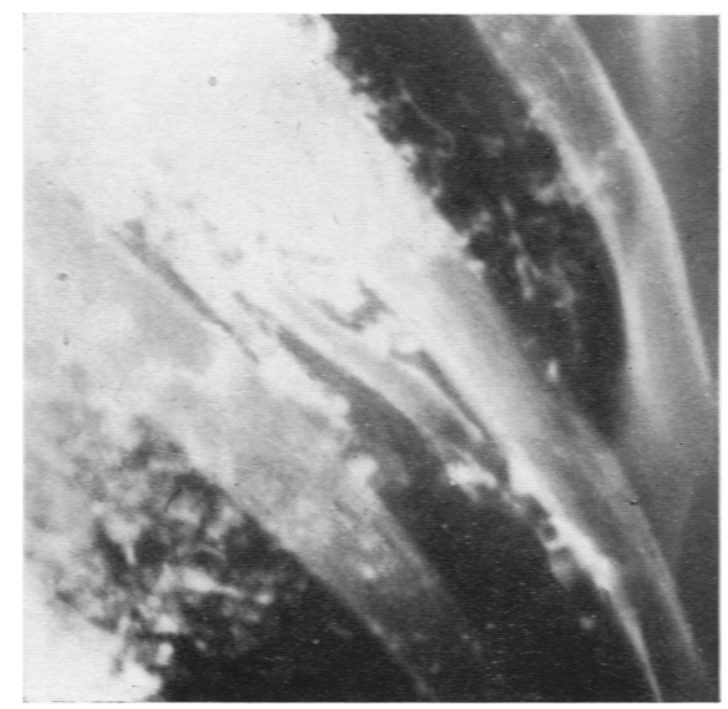

FIG. 4.-Tubular bronchiectasis affecting the upper division of the right lingula bronchi. The lower division is probably ectatic but is not adequately filled. 
honeycomb cysts with cuboidal cell lining to the over-distension of the relatively few alveoli which develop in an atelectatic lobe. Engel (1947) pointed out that atelectasis persisted longer in the lower posterior peravertebral areas of the lung, particularly on the left side, and remarked that these were the usual sites for bronchiectasis. It is possible that atelectasis is particularly common in the neonate with transposition of the viscera, and that it predisposes to the development of bronchiectasis. A further case will illustrate this point.

\section{Case Report}

Case 4. This boy was sent to hospital when 5 weeks old because of a heavy cough and fever, which was thought to be due to pneumonia. The cough has persisted ever since. When 4 months old he was noticed to have dextrocardia and left upper lobe atelectasis.

The patient was the first child (birth weight $9 \mathrm{lb}$.). Pregnancy and delivery were normal.

A second child was born at full term but weighed only $4 \mathrm{lb} .2 \mathrm{oz}$. He suddenly died in the night aged 4 months (cause unknown). The mother and father are alive and well, and are not blood relations. One uncle was born with a deformity; he had a tag on the outer side of each hand, suggestive of a rudimentary sixth finger. One cousin was born without a hand. There is no asthma in the family.

On examination in January, 1944, when aged 7 months, the baby was seen to be well nourished. Frontal bossing was apparent, especially on the left side. He had an extra finger on each hand. The liver was on the left side, and the stomach on the right. The chest percussion note was dull with rales and tubular breath sounds over the left apex anteriorly. A radiograph confirmed the left upper lobe atelectasis and dextrocardia (Fig. 5). The Mantoux test $(1 / 1,000)$ was negative.

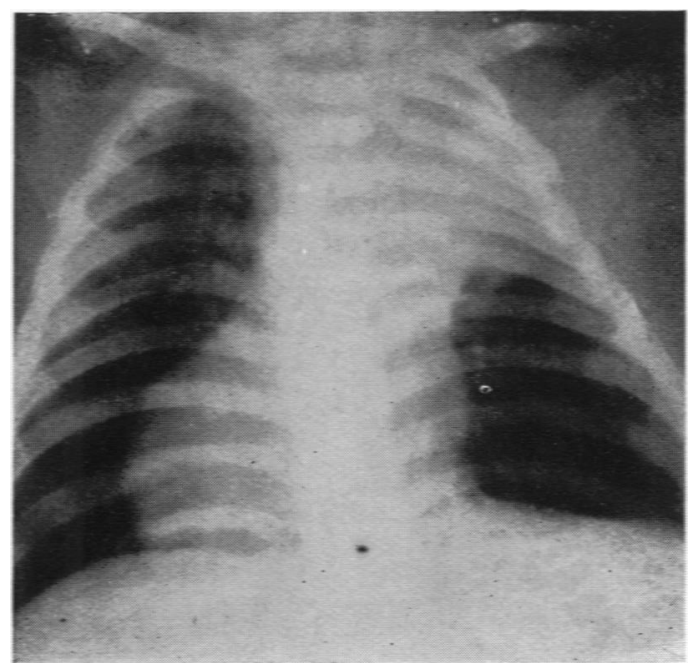

Fig. 5.-At 7 months. Atelectasis of the left upper lobe. Transposition of viscera.

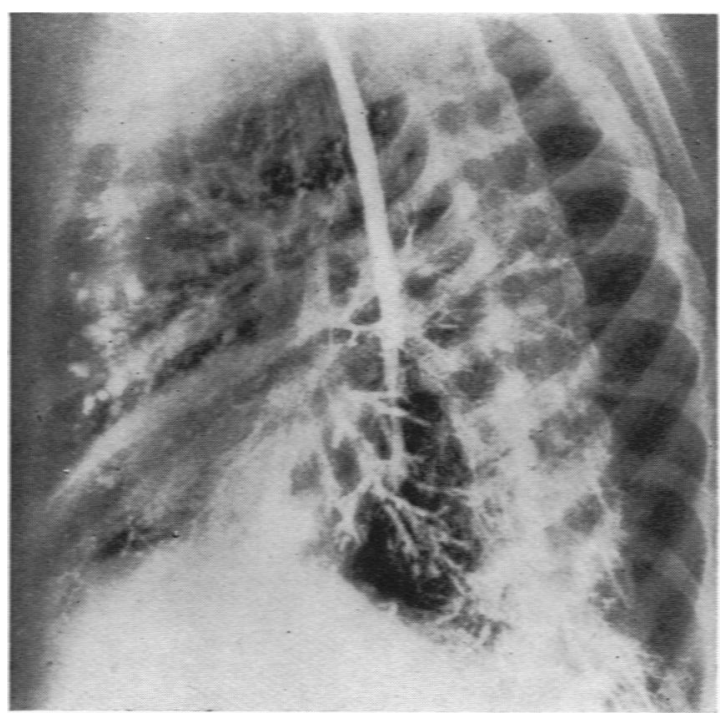

Fig. 6.-Gross saccular bronchiectasis in the pectoral segment of the left upper lobe. Less severe bronchiectasis in some of the other branches of the upper and middle lobes.

Bronchoscopy showed that the left upper lobe bronchus was smaller than normal and congested, but no obstruction was visible.

Two years later (January 16, 1946) slight cough in mornings only was reported. The chest was clear clinically. A radiograph showed some crowding of the left ribs still, and a faint opacity in the left upper lobe area.

On November 15, 1947, cough was present, and the chest showed rhonchi all over. Nasal catarrh was marked. The sinuses were radiologically opaque.

In 1948 bronchography a mirror image bronchial tree was seen. Gross saccular bronchiectasis (Fig. 6) in the pectoral segment of the left upper lobe, and to a lesser degree in some of the bronchi of the upper and middle lobe was seen. The right bronchial tree was normal.

This child had been followed from birth and it was known that he had an atelectatic left upper lobe which took 24 months before it was radiologically re-expanded. The bronchiectasis may have been due to the atelectasis and not a genetical factor. Clinically he is a case of Kartagener's syndrome.

\section{Discussion}

Our knowledge of the congenital deformities that affect the lungs is not very extensive. We know something of the anomalous position of fissures and of the distribution of bronchi from studying the anatomy of the lungs in morbid specimens and from bronchography. Vascular abnormalities are sometimes observed within the lung parenchyma and these may give a bruit on auscultation. Accessory or supernumerary lung lobes have been 
recorded both in the thorax and in the abdomen; Allen (1882), Chiene (1870), and Ruge (1878) described a small accessory lung behind the left lung which derived its blood supply from an intercostal space. Cysts in the mediastinum, lined by bronchial epithelium and without a direct opening into the bronchi or trachea, have been recorded by Carlson (1943), Brown and Robbins (1944), and Allison (1947). There is little doubt that some lung cysts originate from a developmental malformation. These cysts are generally connected to bronchi though they may not open directly into one. The lining epithelium is bronchial in type and the walls may contain portions of other bronchial structures such as elastic tissue, muscle, and cartilage. Lung cysts with a wall structure characteristic of bronchial tissue have been found at necropsy in stillborn foetuses by Meyer (1859), Pappenheimer (1912), Smith (1925), and Wolman (1930).

Cystic disease of lungs has been separated in the past from bronchiectasis because the former is mainly found in young children and is characterized by solitary or multiple round cavities lined by bronchial epithelium, alongside and seldom connected to the bronchi, which themselves are not much dilated. The parenchyma about congenital cysts usually lacks the carbon pigmentation seen in normally aerated lung tissue. Bronchiectasis, on the other hand, has been regarded as a disease affecting children after infancy and adults, in whom the larger, more firm-walled bronchi are widened, thickened, and inflamed, but round cysts seldom occur. It is now known that a cystic appearance in the lung can be acquired and it is suspected that dilatation of the major bronchi may sometimes be congenital in origin.

In the vast majority of cases bronchiectasis is an acquired disease. If it is sometimes congenital it should be possible occasionally to demonstrate it in a stillborn foetus or in a neonate in whom atelectasis or infection have not occurred. Histological proof of congenital malformation is very difficult and requires positive findings such as an irregular arrangement, lack of formation, or hyperplasia of tissues which could not have arisen from post-natal hypertrophy, atrophy, collapse or inflammation. Even bronchogenic cysts found in the newborn generally lack unequivocal evidence of a developmental origin. The bronchi in bronchiectasis are generally overlaid by the alterations produced by inflammation. Hypertrophy of certain stromal layers is occasionally found, but one cannot as a rule maintain that this is hyperplasia.

As direct proof of a developmental origin of bronchiectasis is still lacking, these four cases are presented to add to the weight of circumstantial evidence slowly being accumulated that a congenital factor may be of importance in the disease.

\section{Summary}

Four cases of bronchiectasis associated with complete transposition of the viscera are described. The frequency of bronchiectasis among cases with situs inversus totalis is so much greater than in the general population as to suggest that the bronchiectasis may also be due to a developmental error.

I wish to thank Dr. B. E. Schlesinger and Dr. R. E. Bonham Carter for permission to publish this article, and Miss S. Young for her secretarial help. Rererences
Abbott, M. (1936). 'Atlas of Congenital Cardiac
Disease,' p. 58. New York.

Adams, R., and Churchill, E. D. (1937). J. thorac. Surg., $7,206$.

Allen, W. (1882). J. Anat. Physiol., 16, 605.

Allison, P. R. (1947). Thorax, $2,176$.

Andrews, C. T. (1949). Brit. med. J., 2, 1269.

Araki, B. (1935). Quoted by Cockayne.

Brown, R. K., and Robbins, L. L. (1944). J. thorac. Surg., $13,84$.

Carison, H. A. (1943). I Ibid., 12, 376.

Chiene, J. (1870). J. Anat., Lond., 4, 89.

Clagett, O. T. (1942). Proc. Mayo Clin., 17, 1.

Cockayne, E. A. (1938). Quart. J. Med., 7, 479.

Eliman, P. (1935). Proc. roy. Soc. Med., 28, 333.

Engel, S. (1947). ' The Child's Lung.' London.

Francke, W. (1894). Dtsche. Arch. klin. Med., 52, 125.

Heller, A. (1885). Ibid., 36, 189.

Hinshaw, H. C., and Schmidt, H. W. (1944). Dis. Chest, $10,115$.

Kartagener, M. (1933). Beitr. Klin. Tuberk., 83, 489.

-, and Horlacher, A. (1935). Schweiz. med. Wschr., 65, 782.

LeWald, L. T. (1925). J. Amer. med. Ass., 84, 261.

López Areal, L. (1944). Rev. clin. esp., 14, 378.

Meyer, H. (1859). Virchow's Arch., 16, 78.

Millex, J. A. (1934). J. thorac. Surg., 3, 246.

Nüssel, K., and Helbach, H. (1934). Beitr. Klin. Tuberk., 84, 424.

Olsen, A. M. (1943). Amer. Rev. Tuberc., 47, 435.

Pappenheimer, A. M. (1912). Proc. N.Y. path. Soc., 12, 193.

Pastore, P. N. and Olsen, A. M. (1941). Proc. Mayo Clin., 16, 593 .

Richards, W. F. (1944). Tubercle, Lond., 25, 27.

Ruge, C. (1878). Berl. klin. Wschr., 15, 401.

Sauerbruch, F. von. (1934). Arch. klin. Chir., 180, 312.

Smith, S. (1925). Brit. med. J., 1, 1005.

Strukow, A. I. (1932). Z. Anat. Entw. Gesch., 98, 348.

Torgersen, J. (1946). Acta med. scand., 126, 319.

Wiese, O. (1927). 'Die Bronchiektasien im Kindesalter.' Berlin.

Willson, H. G. (1928). Amer. J. Amat., 41, 97.

Wolman, I. J. (1930). Bull. Ayer clin. Lab., 2, No. 12, p. 49. 